\title{
Design of low frequency acoustic sensor for wheat dough study in kneading and fermentation phases*
}

\author{
NASSAR G, SKAF A., LEFEBVRE F., NONGAILLARD B and DIB R. \\ I.E.M.N. - U.M.R. C.N.R.S. 8520 - D.O.A.E. - Université de Valenciennes - B.P. 311 - \\ 59313 Valenciennes Cedex 09, France.
}

\section{Abstract}

In this work, we developed two acoustic devices to study both critical phases in wheat dough processing: the kneading phase and the fermentation one. The ultrasonic sensor in the kneading phase plays the role of a microphone integrated in the mixer. This sensor represents the mechanical development of the dough in kneading by a curve with critical point. While, in the fermentation phase, the paste is subjected to an acoustic vibration. This technique uses a mechanical pulse emitter and a low-frequency broadband acoustic receiver. The experimental set up shown here is able to monitor in situ the evolution of the physical properties of the matter in kneading and fermentation phases. These techniques enable the dough evolution kinetic assessment with varying additive elements and technological parameters.

* This work has been supported by the FEDER \& the Region Nord Pas de Calais 


\section{Introduction}

Bread making is a very important and complicated process in food industry. Although people have practised moulding for a very long time, quantitative understanding of physical processes is still very limited. For example, the volume expansion is related to leaven component, moisture content as well as yeast type and activity, etc. Quantitative description of texture changes and other parameters are still very primitive. One of the possible reasons for this is that several fundamental physical complex processes are coupled. During the volume growth and texture modification, dough is subjected both to shear and extensional deformations. During fermentation, dough specific volume is increased due to bubble growth from yeast gas production. This stage is crucial since gas bubble size volume distribution is a quantitative indicator of final quality.

In fact, the complexity of dough is not restricted to its chemical composition, but also includes physical properties (Hoseney, 1998). Rare are works dealing with the characterization of the kneading phase. Despite large changes in the dough physical properties during kneading, there is little information in the literature concerning the study of these changes in kneading process. It was found that changes in linear viscoelastic properties of dough with kneading time were small for samples prepared in a number of laboratory scale mixers (Abdelrahman \& al., 1986; Mani \& al., 1992). From a structural point of view, evolving dough can be considered as a porous material consisting of gas cells embedded in a viscoelastic paste. The characteristics of such material mainly depend of the properties of the flour, the quantity of added water, the air incorporated into it and the kneading conditions. Generally, rheological testing has been used to follow the changes of the fundamental mechanical properties of flour-andwater dough. Small amplitude oscillatory dynamic testing is also one of the possibilities to examine the fundamental viscoelastic properties of such dough (Salvador \& al., 
2005). Some other works (Hibberd, 1970; Smith \& al.,1970; Khatkar \& al., 2002) describe the capability of the viscoelastic nature of dough to retain gas component. In order to obtain some information on the physical changes during the formation of the product in the kneading phase, models have been studied and show that dynamic methods are useful for understanding viscoelastic changes (Eliasson, 1986).

Although it is well established that the changes that occur in the starch granules are a function of both temperature and water content, the part played by other ingredients such as $\mathrm{NaCl}$ or sucrose is still not fully understood. Although yeast plays a crucial role in bread-making, almost all rheological testing and empirical studies are performed on dough prepared without yeast, thus eliminating the time-dependent effect of yeast on dough viscoelastic properties. Nevertheless, a number of studies concerning the rheological properties of yeasted dough have been conducted (Esselink \& al., 2003; Newberry \& al., 2002), in some of which the yeast has been allowed to remain active during the measurements (Oliver \& al., 1997). The fundamental rheological properties of fermenting dough are difficult to determine because of its heterogeneous nature and the continuous changes in the system, so measurements must be made carefully as long as the system is stabilized.

At present, it is difficult to measure dough development directly. So, with the aim to understand the complex phenomena governing the development of dough in the phase of kneading and fermentation, this study brings, by the originality of the acoustic technique used, the necessary knowledge to understand the development of bread dough in the kneading phase and throughout the fermentation phase according to several technological parameters.

It should be noted that our study follows two different ways: the study of kneading process by using two types of flour (strong and soft) and the study of fermentation 
process with only one type of flour (baker flour) but by varying the ingredients and the additives.

\section{Materials and methods}

\section{Dough}

Table 1 shows the characteristics and the references of flours and ingredients used in this study.

\begin{tabular}{|c|c|}
\hline Components & References \\
\hline Baker flour & BIFLOR 290203 \\
\hline Yeast & SPI 2543 \\
\hline Alpha amylase & Enz 421 \\
\hline Inactive dry yeast powder & --- \\
\hline Purified sea salt & --- \\
\hline Distilled water & --- \\
\hline & \\
\hline
\end{tabular}

Table 1

Dough was kneaded in an Alveograph NG Chopin. The composition of the basic samples being useful as a starting formulation appears in table 2 .

\begin{tabular}{|c|c|c|c|}
\hline Components & Flour & Water & Salt \\
\hline$\%$ of Flour mass & $100 \%$ & $60 \%$ & $2 \%$ \\
\hline Mass $(\mathrm{g})$ & $200 \mathrm{~g}$ & $120 \mathrm{~g}$ & $4 \mathrm{~g}$ \\
\hline
\end{tabular}

Table 2

The mixer develops the dough by the mean of rotating a flat blade with previously controlled torque and temperature $\left(25 \pm 0.5^{\circ} \mathrm{C}\right)$. The time of kneading operation is 15 minutes. The protocol of samples preparation consists to mix the dry ingredients in the mixer during one minute and add the water to them without stopping the rotation of the blade. 


\section{Acoustic kneading analyser}

The analysis of the development of the dough in this phase of preparation is provided on line with a piezoelectric sensor embedded in the plane zone of the kneading tank (Figure 1). This sensor has a diameter of $20 \mathrm{~mm}$ and a $2 \mathrm{~mm}$ thickness. It is used as a microphone which captures the noise due to the movement of the dough rolled continuously by the blade. Each time the blade passes in front of the sensor, this one sends an electric signal reflecting the physical properties of the dough at this moment. After digitalization, the signals are processed on a computer for a better understanding of the noise emanating from the mixer.

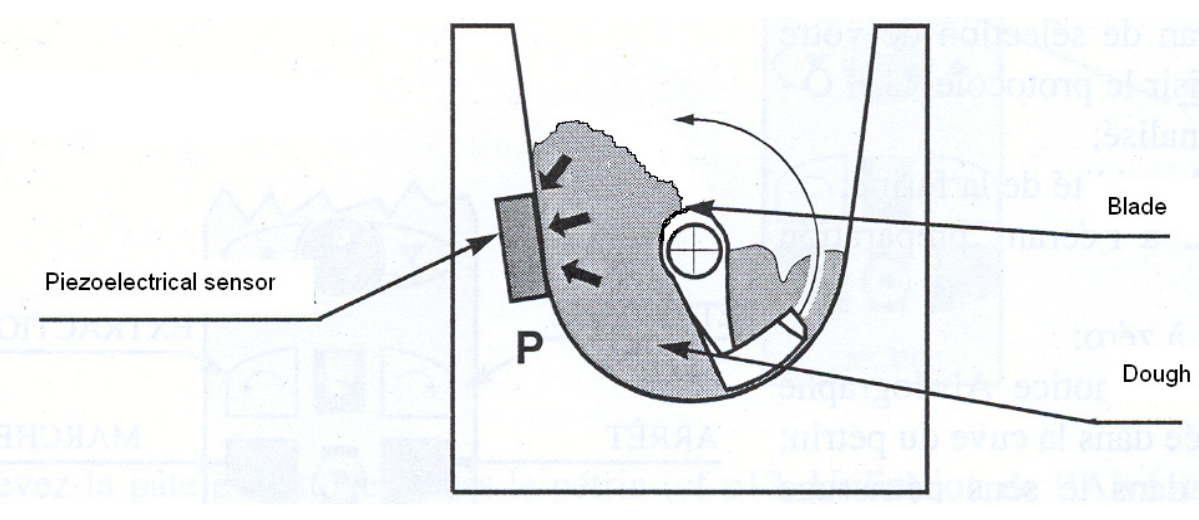

\section{Figure 1.}

\section{Acoustic fermentation analyser}

After the kneading phase was completed, the dough is transferred in another acoustic measuring cell intended to follow the evolution of the physical properties in fermentation phase (Figure 2). Five minutes are considered for the transfer.

The acoustic cell is composed of an electromechanical shock generator which produces an impact at the bottom of the sample. A $10 \mathrm{~cm}$ diameter composite receiving disc with $2 \mathrm{~mm}$ thickness is put in contact with the dough on the opposite face. This sensor provides the reception of the shock crossing the dough. Emission, reception, rate of measurements and data processing are ensured by a computer driven system. 


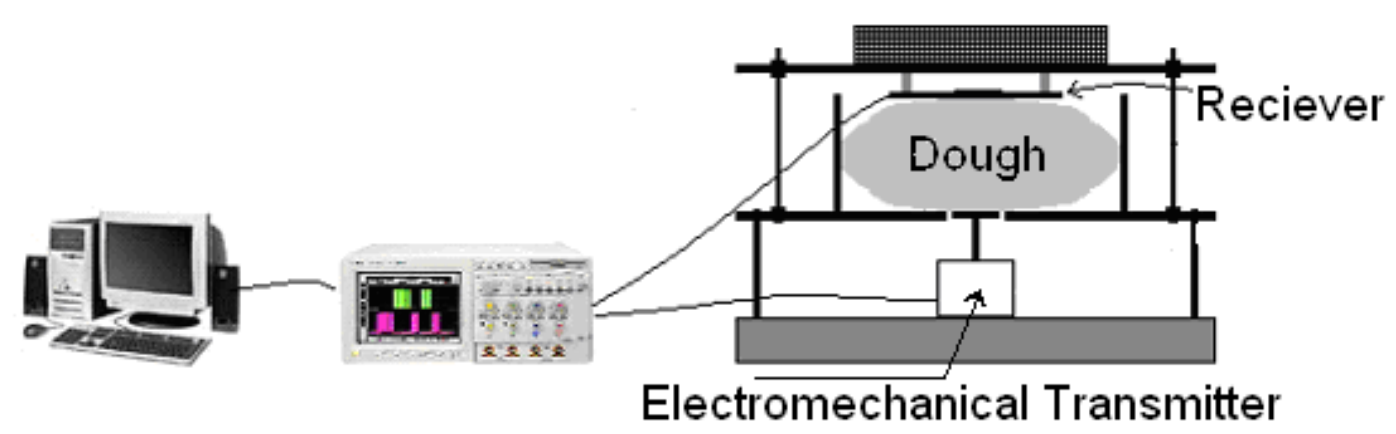

Figure 2.

\section{Results}

\section{Dough kneading step}

In order to understand the phenomena governing the dough development in the kneading phase, two kind of flour were considered: soft and strong flour. The applied procedure has been given in the previous paragraph. The temperature of the kneading cell is maintained closed to $25 \pm 0.5^{\circ} \mathrm{C}$ and the kneading duration is 15 minutes.

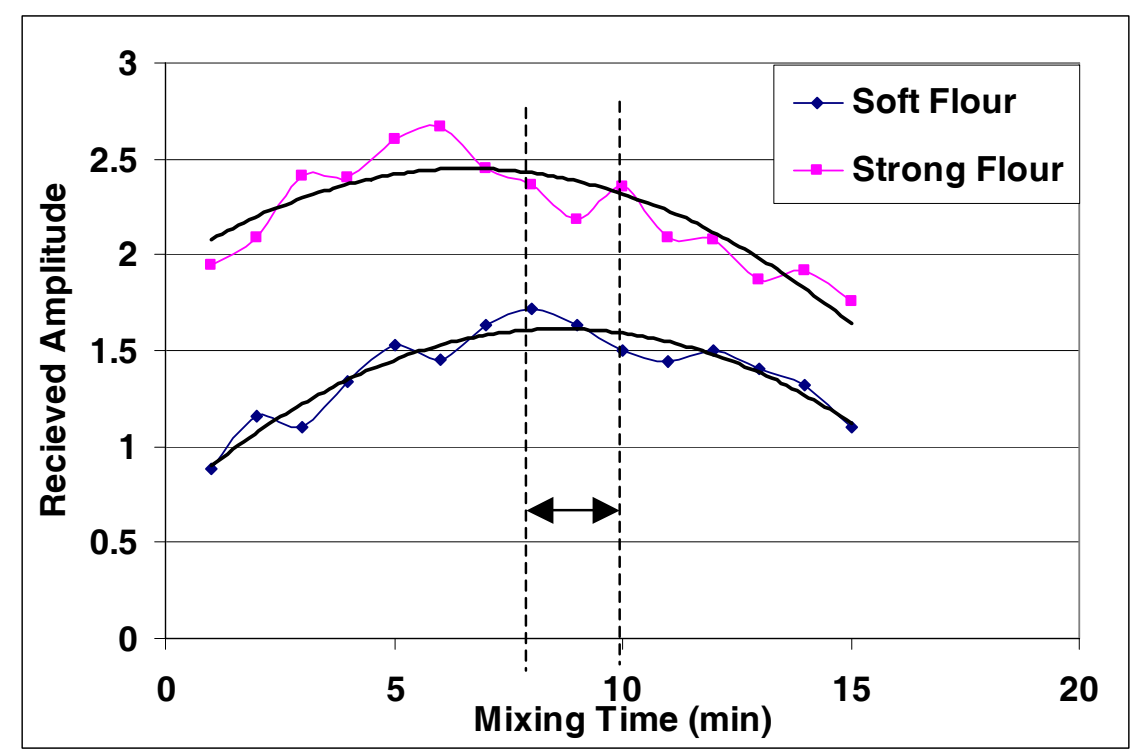

Figure 3.

Figure 3 shows the evolution of the maximum of the amplitude of the signal received by the sensor embedded in the wall of mixer. We can notice that the curves start with a 
value and reach a maximum value which are a function of the kind of flour considered. In the experiment considered here, the strong flour starts with an amplitude level higher than that of the soft flour and a maximum value is reached approximately 3 minutes before that corresponding to the strong flour. These results, which are in agreements with the literature (Zheng \& al., 2000), indicate a critical phase transition defining an optimal development of dough.

\section{Dough fermentation step}

In this step, measurements were taken in a protected environment in order to avoid the dough's skin drying which can consequently distort the results.

While keeping the distance between transmitter and receiving constant (Figure 2), the curves of figure 4 show the evolution of the central frequency of the received signal through the dough according to several technological parameters. It can be noticed that links between technological choices in the preparation of dough and the evolution of it in the fermentation phase can be clearly established with the use of our acoustic method.

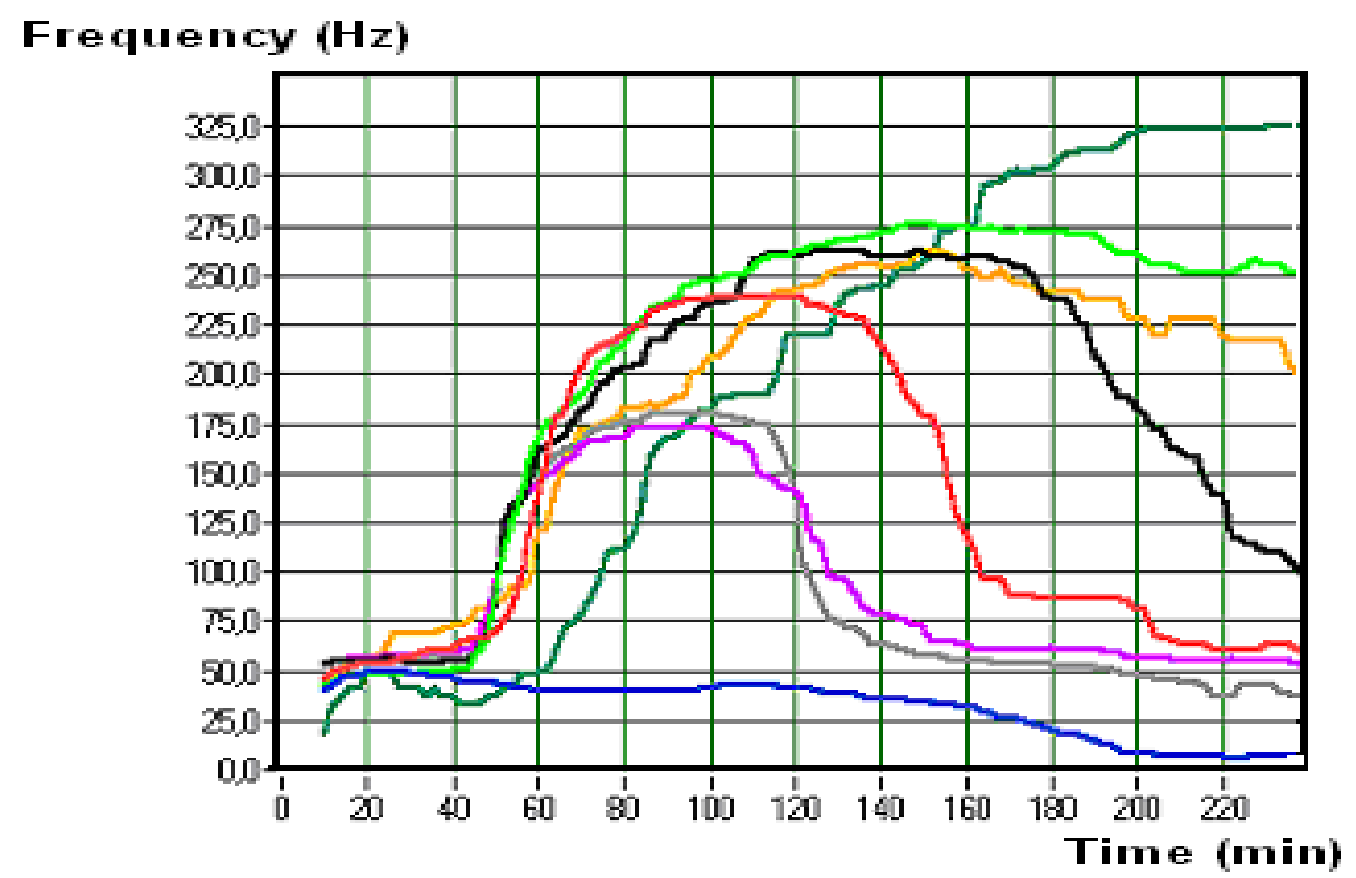




\begin{tabular}{|c|c|c|c|c|c|c|c|}
\hline $\begin{array}{c}\text { Without } \\
\text { Yeast } \\
\left(35^{\circ} \mathrm{C}\right)\end{array}$ & $\begin{array}{c}\text { Yeast } \\
\left(35^{\circ} \mathrm{C}\right)\end{array}$ & $\begin{array}{c}\text { Bromate } \\
\left(35^{\circ} \mathrm{C}\right)\end{array}$ & $\begin{array}{c}\text { Ascorbique } \\
\text { Acide } \\
\left(35^{\circ} \mathrm{C}\right)\end{array}$ & $\begin{array}{c}\text { L Cystéine } \\
\left(35^{\circ} \mathrm{C}\right)\end{array}$ & $\begin{array}{c}\text { Inactive } \\
\text { Yeast } \\
\left(35^{\circ} \mathrm{C}\right)\end{array}$ & $\begin{array}{c}\text { Yeast } \\
\left(25^{\circ} \mathrm{C}\right)\end{array}$ & $\begin{array}{c}\text { Bromate } \\
\left(25^{\circ} \mathrm{C}\right)\end{array}$ \\
\hline $\mathrm{A}$ & $\mathrm{B}$ & $\mathrm{C}$ & $\mathrm{D}$ & $\mathrm{E}$ & $\mathrm{F}$ & $\mathrm{A}$ & $\mathrm{B}$ \\
\hline & & & & & & & \\
\hline
\end{tabular}

Figure 4 .

Doughs used in these experiments are marked by a letter (A-F) and formulations are given in the tables on next page.

\section{Technological parameters}

Dough A : Reference Dough

\begin{tabular}{|c|c|c|c|}
\hline Components & Flour & Water & Salt \\
\hline \%Flour & $100 \%$ & $60 \%$ & $2 \%$ \\
\hline Mass $(\mathrm{g})$ & $200 \mathrm{~g}$ & $120 \mathrm{~g}$ & $4 \mathrm{~g}$ \\
\hline
\end{tabular}

Dough B:

\begin{tabular}{|c|c|c|c|c|c|}
\hline Components & Flour & Water & Salt & Yeast & Alpha-amylase \\
\hline \%Flour & $100 \%$ & $60 \%$ & $2 \%$ & $0,4 \%$ & $3 \mathrm{ppm}$ \\
\hline Mass $(\mathrm{g})$ & $200 \mathrm{~g}$ & $120 \mathrm{~g}$ & $4 \mathrm{~g}$ & $0,8 \mathrm{~g}$ & $100 \mu \mathrm{l}(0,6 \mathrm{~g} / 100 \mathrm{ml})$ \\
\hline
\end{tabular}

Dough C:

\begin{tabular}{|c|c|c|c|c|c|c|}
\hline Components & Flour & Water & Salt & Yeast & Alpha-amylase & Bromate \\
\hline \%Flour & $100 \%$ & $60 \%$ & $2 \%$ & $0,4 \%$ & $3 \mathrm{ppm}$ & $160 \mathrm{ppm}$ \\
\hline Mass $(\mathrm{g})$ & $200 \mathrm{~g}$ & $120 \mathrm{~g}$ & $4 \mathrm{~g}$ & $0,8 \mathrm{~g}$ & $\begin{array}{c}100 \mu \mathrm{l}(0,6 \mathrm{~g} / \\
100 \mathrm{ml})\end{array}$ & $3,2 \mathrm{ml}(0,5 \mathrm{~g} / 50 \mathrm{ml})$ \\
\hline
\end{tabular}

Dough D:

\begin{tabular}{|c|c|c|c|c|c|c|}
\hline Components & Flour & Water & Salt & Yeast & Alpha-amylase & ascorbique Acide \\
\hline \%Flour & $100 \%$ & $60 \%$ & $2 \%$ & $0,4 \%$ & $3 \mathrm{ppm}$ & $80 \mathrm{ppm}$ \\
\hline Mass $(\mathrm{g})$ & $200 \mathrm{~g}$ & $120 \mathrm{~g}$ & $4 \mathrm{~g}$ & $0,8 \mathrm{~g}$ & $\begin{array}{c}100 \mu \mathrm{l}(0,6 \mathrm{~g} / \\
100 \mathrm{ml})\end{array}$ & $\begin{array}{c}1,6 \mathrm{ml}(0,5 \mathrm{~g} / 50 \mathrm{ml}) \\
\end{array}$ \\
\end{tabular}

\section{Dough E:}

\begin{tabular}{|c|c|c|c|c|c|c|}
\hline Components & Flour & Water & Salt & Yeast & Alpha-amylase & L Cystéine \\
\hline \%Flour & $100 \%$ & $60 \%$ & $2 \%$ & $0,4 \%$ & $3 \mathrm{ppm}$ & $80 \mathrm{ppm}$ \\
\hline Mass $(\mathrm{g})$ & $200 \mathrm{~g}$ & $120 \mathrm{~g}$ & $4 \mathrm{~g}$ & $0,8 \mathrm{~g}$ & $\begin{array}{c}100 \mu \mathrm{l}(0,6 \mathrm{~g} / \\
100 \mathrm{ml})\end{array}$ & $1,6 \mathrm{ml}(0,5 \mathrm{~g} / 50 \mathrm{ml})$ \\
\hline
\end{tabular}

\section{Dough F:}

\begin{tabular}{|c|c|c|c|c|c|c|}
\hline Components & Flour & Water & Salt & Yeast & Alpha-amylase & $\begin{array}{c}\text { Inactive Yeast } \\
\text { Powder }\end{array}$ \\
\hline \%Flour & $100 \%$ & $60 \%$ & $2 \%$ & $0,4 \%$ & $3 \mathrm{ppm}$ & $0,8 \%$ \\
\hline Mass $(\mathrm{g})$ & $200 \mathrm{~g}$ & $120 \mathrm{~g}$ & $4 \mathrm{~g}$ & $0,8 \mathrm{~g}$ & $\begin{array}{c}100 \mu \mathrm{l}(0,6 \mathrm{~g} / \\
100 \mathrm{ml})\end{array}$ & $1,6 \mathrm{~g}$ \\
\hline
\end{tabular}




\section{Conclusion}

This work has examined two possible uses of acoustic methods to characterize dough process. The first one uses an embedded acoustic sensor in the kneading cell and working like a microphone. The measurements can be used to determine the critical time of dough development in kneading stage. We have shown that the received signals in this technique evolve differently according to properties of the product used: soft and strong flour. The second one uses the propagation of a mechanical shock through the dough in the fermentation phase. The results from this technique in the fermentation phase appear to be sensitive to the different type of technological parameters in dough process. A wider range of additives should be investigated for baker flour dough. Nevertheless, from these results, it appears that the acoustic measurement through the frequency deviation can potentially be used as an effective on line dough quality control technique. 


\section{References}

Abdelrahman, A.A., and Spies, R.D., Dynamic rheological studies of dough systems. In "Fundamentals of dough rheology", (Faridi \& Faubion), American association of cereal chemists, St. Paul, Minnesota (1986), pp. 87-103.

Eliasson, A.C., "Viscoelastic behaviour during the gelatinisation of starch. I. Comparison of wheat, maize, potatoand waxy-berlea starches". Journal of texture studies, 17, (1986), 253-265.

Esselink, E., Van Aalst, H., Maliepaard, M., Henderson, T.M.H., Hoekstra, N.L.L. and Van Duynhoven, J., "Impact of industrial doughprocessing on structure: a rheology, nuclear magnetic resonance and electron microscopy study". Cereal chemistry, 80, (2003), 419-423.

Hibberd, G.H., "Dynamic viscoelastic behaviour of wheat flour doughs", Rheologica Acta, 9, (1970), 497-500.

Hoseney, R. C., Glass transition and its role in cereals. In "Principles of cereal science and technology", $2^{\text {nd }}$ edition, (1998), pp. 307-320.

Khatkar, B.S. and Schofield, J.D., "Dynimic rheology of wheat flour dough. I. Nonlinear viscoelastic behaviour". Journal of science food and agricultural, 82, 827-829.

Mani, K., Eliasson, A.C., Lindahl, L. and Trägardh, C., "Rheological properties and breadmaking quality of wheat flour doughs made with different dough mixers, Cereal Chemistry, 69, (1992), 222-225.

Newberry, M.P., Phan-Thien, N., Larroque, O.R., Tanner, R.I. and Larsen, N.G. "Dynamic and elongation rheology of yeasted bread doughs". Cereal Chemistry, 79, (2002), 874-879. 
Oliver, G. and Brock, C.J., "A rheological study of mechanical dough development and long fermentation processes for cream-craker dough production". Journal of science food and agricultural, 74, (1997), 294-300.

Salvador, A. Sanz, T. and Fiszman, S.M., "Dynamic rheological characteristics of wheat flour-water doughs. Effect of adding $\mathrm{NaCl}$, sucrose and yeast", Food Hydrocolloids, In Press, (2005),1-7.

Smith, J.R., Smith, T.L. and Tschoegl, N.W., "Rheological properties of wheat flour doughs. III Dynamic shear modulus and its dependence on amplitude, frequency and dough composition”. Rheologica Acta, 9, (1970), 239-252.

Zheng, H., Morgensternt, M.P., Campanella, O.H., and Larsen, N.G., "Rheological properties of dough during mechanical dough development". Journal of cereal science, 32, (2000), 293-306. 